\title{
Protective effect of extract of the Camellia japonica L. on cerebral ischemia-reperfusion injury in rats
}

\author{
Efeito protetor do extrato da Camellia japonica L. na lesão de reperfusão isquêmica \\ cerebral em ratos
}

Weizhuo Lu', Ling XV ${ }^{1}$, Jiyue Wen²

\begin{abstract}
Objective: We investigated the protective effect of the extract of the Camellia japonica $L$. flower on cerebral ischemia-reperfusion injury in rats. Methods: The rat ischemia-reperfusion injury was induced by middle cerebral artery occlusion for 90 minutes and reperfusion for 48 hours. The animals received an intravenous injection once a day of 20, $40,80 \mathrm{mg} / \mathrm{kg}$ extract of C. japonica for three consecutive days before the ischemia reperfusion. The learning and memory function, the infarct volume, serum malondialdehyde (MDA) level and lactate dehydrogenase activity, and extravasation of immunoglobulin G (IgG) into cerebral parenchyma were assessed as the cell damage index. Results: Pretreatment with extract of $C$. japonica markedly reduced the infarct volume, serum malondialdehyde level and lactate dehydrogenase activity, and markedly inhibited the extravasation of IgG. Moreover, pretreatment with extract of C. japonica may also inhibit the learning and memory deficits induced by an ischemia-reperfusion injury. Conclusion: It was concluded that pretreatment with extract of $C$. japonica has a protective effect on cerebral ischemia-reperfusion injury in rats.
\end{abstract}

Keywords: Brain ischemia; blood-brain barrier.

\section{RESUMO}

Objetivo: Investigamos o efeito protetor do extrato da flor de Camellia japonica L. (ECJ) na lesão de reperfusão isquêmica cerebral (I/R) em ratos. Métodos: A lesão de I/R de rato foi induzida por uma oclusão da artéria cerebral média por 90 minutos e reperfusão por 48 horas. Os animais receberam uma injeção intravenosa uma vez ao dia de 20, 40, $80 \mathrm{mg} / \mathrm{kg}$ de ECJ por três dias consecutivos antes da I/R. A função de aprendizagem e memória, o volume do infarto, o nível sérico de malondialdeído (MDA), a atividade da desidrogenase láctica e o extravasamento de imunoglobulina (IgG) no parênquima cerebral foram avaliados como índices de dano celular. Resultados: O pré-tratamento com ECJ reduziu acentuadamente o volume do infarto, o nível sérico de MDA e a atividade da desidrogenase láctica, e inibiu marcadamente o extravasamento de lgG. Além disso, o pré-tratamento com ECJ também poderia inibir os déficits de aprendizado e memória induzidos pela lesão de I/R. Conclusão: O pré-tratamento com ECJ tem um efeito protetor contra lesão cerebral de I/R em ratos.

Palavras-chave: Isquemia encefálica; barreira hematoencefálica.

Ischemic stroke is one of the leading causes of disability and mortality ${ }^{1}$. On the one hand, stroke leads to complex processes, including intracellular calcium overload, free radicalsmediated toxicity and disruption of the blood brain barrier (BBB), which lead to acute neurological deficit ${ }^{2}$. On the other hand, stroke can also lead to neurodegeneration ${ }^{3}$. The tissue plasminogen activator ( $\mathrm{t}-\mathrm{PA}$ ) is the only FDA-approved drug for clinical treatment of acute ischemic stroke. However, the t-PA treatment often induces secondary impairments, and can cause severe neurodegeneration, such as cerebral ischemia-reperfusion injury ${ }^{4}$. Therefore, the main priority is to find new drugs for ischemic stroke treatment.

Many plant extracts and/or constituents are being proven to have protective effects in various neurodegenerative disorders ${ }^{3}$. Camellia japonica $\mathrm{L}$. is a member of the tea family, widely cultivated in China, Japan, Korea and other parts of the world. Previous studies have demonstrated that C. japonica possesses various biological activities, such as

${ }^{1}$ Hefei Technology College, Medical Branch, Hefei, China;

${ }^{2}$ Anhui Medical University, Department of Pharmacology, Hefei, China.

Jiyue Wen (iD https://orcid.org/0000-0002-7602-1727

Correspondence: Jiyue Wen; Department of Pharmacology, Anhui Medical University, Hefei, China; E-mail: wenjiyue139@aliyun.com

Conflict of interest: There is no conflict of interest to declare.

Support: This work was supported by a grant from the Natural Science Foundation of Hefei Technology College (No. 201814KJA009), and supported by Grants for Scientific Research of BSKY (No. XJ201612) from Anhui Medical University.

Received 21 April 2018; Received in final form 18 July 2018; Accepted 28 September 2018. 
an anti-allergic effect ${ }^{5}$, antibacterial activity ${ }^{6}$, antioxidant activity $^{7,8,9}$, and endothelium-dependent relaxation of the coronary artery. Particularly, the extracts obtained from the fruit of $C$. japonica have strong cardiovascular protection effects ${ }^{3,10}$. Our previous study demonstrated that the extract of $C$. japonica obtained from fresh flowers has a protective effect on hippocampal neurons subjected to an anoxia-reoxygenation injury ${ }^{11}$. But it is not clear whether the extract of $C$. japonica has a protective effect on cerebral ischemia-reperfusion injuries in rats.

Thus the present study was designed to demonstrate the possible effect of extract of $C$. japonica obtained from flowers on a rat cerebral ischemia-reperfusion injury and its mechanism, with normal saline and nimodipine used as negative and positive controls, respectively, according to our previous study ${ }^{12}$. Nimodipine has also been used as a positive control in another experimental cerebral ischemia-reperfusion study ${ }^{13}$. The infarct volume and lactate dehydrogenase (LDH) activity in serum were considered as indicators for the neuron damage index after ischemia-reperfusion injury; the Morris maze test and the Step-down test were used to evaluate learning and memory deficits; the presence of serum immunoglobulin $\mathrm{G}$ (IgG) in brain parenchyma was measured as a marker of BBB damage; and the serum malondialdehyde (MDA) level was measured as an oxidative stress marker.

\section{METHODS}

\section{Preparation of extract of $\mathrm{C}$. japonica}

The ethanolic extracts obtained from fresh flowers of C. japonica was purchased from Xian Wanfang Biological Technology Co., Ltd (Xian, China). According to the supplier, the flowers of $C$. japonica were washed, air-dried at $70^{\circ} \mathrm{C}$ and extracted at $30^{\circ} \mathrm{C}$ for three days in $100 \%$ methanol. The extract solution was then filtered and vacuum-evaporated until dry.

\section{Drugs and reagents}

Nimodipine was purchased from the Shandong Fangming Pharmaceutical Group Co. Ltd. (Shandong, China). The 2,3,5-triphenyltetrazolium chloride (TTC), MDA and LDH test kits were purchased from Nanjing Jiancheng Biological Company (Nanjing, China). The rat IgG ELISA kit was purchased from Abcam Trading (Shanghai) Company, Ltd. (Shanghai, China).

\section{Animals}

Adult Sprague Dawley rats (male to female: 1:1) weighing 220-250g were purchased from Anhui Medical University Animal Center. The animals were housed in the Animal Center of Hefei Technical College with free access to food and water, with a relative humidity of $54 \pm 2 \%$ and a controlled temperature of $22 \pm 2^{\circ} \mathrm{C}$. All experimental procedures conformed to the Ethics Review Committee of Hefei Technical College, which follows the protocol outlined in the Guide for the Care and Use of Laboratory Animals published by the US National Institutes of Health (NIH publication number 86-23, revised 2011).

\section{Experimental designation}

Rats were randomly divided into the following seven groups: sham, model, control, extract of $C$. japonica pretreatment $(20,40,80 \mathrm{mg} / \mathrm{kg})$ and nimodipine (2mg/kg) groups. In the extract of $C$. japonica pretreatment and nimodipine groups, the rats were given extract of $C$. japonica at a dose of 20,40 or $80 \mathrm{mg} / \mathrm{kg}$ (prepared with $0.9 \%$ sodium chloride) or nimodipine at a dose of $2 \mathrm{mg} / \mathrm{kg}$ by intragastric administration, respectively, once a day for three consecutive days before ischemia-reperfusion; the rats in the control group were administered $0.9 \%$ sodium chloride; rats of the model group did not receive any drug or reagent.

\section{Rat cerebral ischemia-reperfusion model ${ }^{12}$}

The rat cerebral ischemia-reperfusion injury was created by 90 minutes of middle cerebral artery occlusion and 48 hours of reperfusion. Rats were deeply anesthetized with chloral hydrate $(350 \mathrm{mg} / \mathrm{kg})$. A nylon suture was introduced through the internal carotid artery to block the origin of the middle cerebral artery branch for 90 minutes. The suture was then withdrawn from the middle cerebral artery for reperfusion for 48 hours. Body temperature was maintained at $37^{\circ} \mathrm{C}$ throughout the surgery on a heated platform. The rats of the sham group were not exposed to ischemic stroke. The animals of the extract of $C$. japonica, control and nimodipine groups received a once-a-day extract of $C$. japonica, nimodipine or saline for three consecutive days by intragastric administration before ischemic stroke.

\section{Step-down test}

At 48 hours after the reperfusion, the rat was placed on the floor of the jumping apparatus; the floor was made of parallel stainless steel bars ${ }^{14,15}$. After adapting for five minutes, the rat was exposed to a $36 \mathrm{~V}$ electric foot shock. The latency of the rat jumping onto the elevated platform, and the frequency of it jumping down from platform to the floor, receiving electric shocks within five minutes, were assessed as the learning latency and the number of learning errors, respectively. The following day, the rat was placed directly on the platform, and the latency and frequency of it jumping down onto floor to receive electric foot shocks within five minutes, were recorded for assessing memory latency and number of memory errors, respectively.

\section{Morris water maze test}

The pool $(150 \mathrm{~cm} \times 150 \mathrm{~cm} \times 60 \mathrm{~cm})$ of the Morris water maze was divided into SW, NW, NE and SE quadrants; the platform was located in the center of the SW quadrant. The pool 
was filled with water $\left(22 \pm 2^{\circ} \mathrm{C}\right)$ to a depth of $21 \mathrm{~cm}$ and $1 \mathrm{~cm}$ higher than the platform. Nontoxic titanium dioxide powder was added to the water to make the water opaque. The movement of the rat in the maze was recorded by a computerized video tracking system ${ }^{14,16,17}$. The procedure was divided into two phases: place navigation and spatial probe. In the place navigation trial, all rats received four trials each day with an inter-trial interval of five minutes for four consecutive days; each rat was put into the water at each of the four quadrants, respectively. The rat was allowed to swim freely until it found and stayed on the platform. The time required to find and stay on the platform is known as the escape latency. If a rat failed to find the escape platform within 60 seconds, it was gently guided to the platform and allowed to stay there for 15 seconds before the next trial, and the escape latency was recorded as 60 seconds. The starting point of the subsequent trial was carried out in a clockwise direction. The result of the four trials of each day was expressed as the average escape latency.

In the probe trial, the platform was removed. The rats were put into the water at the NE quadrant and allowed to swim freely for 60 seconds. The number of entries into the SW quadrant (platform location), time and distance of the rat crossing the SW quadrant were recorded.

\section{Determination of the percentage of infarct volume ${ }^{12,18}$}

To determine the percentage of infarct volume, the brain was sliced coronally at $2 \mathrm{~mm}$ intervals using a brain matrix. Subsequently, the tissue slices were incubated in the dark in $2 \%$ TTC in phosphate-buffered solution at $37^{\circ} \mathrm{C}$ for $30 \mathrm{~min}$ utes, and then placed in $4 \%$ paraformaldehyde for $10 \mathrm{~min}$ utes. The nonischemic area was stained red; the infarct area was not stained and presented as pale. Stained brain slices were photographed to delineate the area of infarct size using Image J, version 1.6 software (National Institutes of Health, Bethesda, MD, USA). The total infarct volume was calculated by summation of the infarcted area $\left(\mathrm{mm}^{2}\right)$ of each slice and multiplied by the thickness of the slice $(2 \mathrm{~mm})$. The percentage of infarct volume was then determined.

\section{Measurement of LDH activity and MDA level}

After the Step-down test and Morris water maze test, the blood of each rat was collected for centrifugation for $10 \mathrm{~min}$ utes at 4,000 g, and the serum transferred into another tube. The MDA level and the LDH activity were measured using a biochemistry assay kit (Jiancheng Bioengineering Ltd, Nanjing, China) following the manufacturer's manual.

\section{Measurement of serum IgG present in brain parenchyma}

A commercial rat IgG ELISA kit (Abcam Trading (Shanghai) Company Ltd. Shanghai, China) was used to measure the blood IgG in brain parenchyma, providing an indirect measurement of the BBB permeability, as a compromised BBB influences the IgG present in brain parenchyma. We therefore measured the IgG in $100 \mu \mathrm{g}$ protein of brain parenchyma, prepared from the cortex and subcortex of the rat brain, respectively.

\section{Statistical analysis}

All experimental data are presented as mean \pm SD. The SPSS 17.0 software was used for statistical analysis, the significance of differences between groups analyzed by Dunnett's test. Statistical significance was considered when $\mathrm{p}<0.05$.

\section{RESULTS}

\section{Effect of extract of $C$. japonica on impairment of rat learning and memory function after cerebral ischemia-reperfusion injury}

The Step-down test in rats is a classical method to study the dysfunction oflearning and memory after cerebral injury ${ }^{19}$. Likewise, in this study, we followed the same approach to investigate the effect of extract of C.japonica on the dysfunction of learning and memory in rats injured by cerebral ischemia-reperfusion. The results are shown in Figure 1. Cerebral ischemia-reperfusion significantly increased learning latency and the number of learning and memory errors (compared with the sham group, $\mathrm{p}<0.01$ ), which were notably alleviated when rats were pretreated with 40 or $80 \mathrm{mg} / \mathrm{kg}$ extract of $C$. japonica (compared with the model group, $\mathrm{p}<0.01$ ). Pretreatment with $2 \mathrm{mg} / \mathrm{kg}$ nimodipine had a similar protective effect on learning and memory deficits.

\section{Effects of extract of $C$. japonica on impairment of rat place navigation and spatial probe ability}

The Morris maze test is a well-proven method for evaluating place navigation and spatial ability to assess spatial reference memory in rodents. The procedure is divided into two phases: place navigation and spatial probe ${ }^{20}$. In the place navigation trial, rats were trained to find the escape platform. Each group of rats exhibited a similar ability of finding the escape platform on the first day of training; the average escape latencies among all groups did not show obvious differences (Figure 2A). As shown in Figure 2B-2D, the average escape latencies of all groups decreased markedly from the second to the fourth day of training, but the average latency of the model group was obviously longer than that of the sham group on the third and fourth days. While, pretreatment with extract of C.japonica (40 and $80 \mathrm{mg} / \mathrm{kg}$ ) markedly inhibited the prolongation of the escape latency of rats, the pretreatment with $2 \mathrm{mg} / \mathrm{kg}$ nimodipine had a similar effect.

In the spatial probe trial, the number of entries, the time and distance of crossing to the platform location were measured. As shown in the Table, the number of entries and both proportions of time and distance of crossing to the platform in the model rat group decreased significantly compared with 

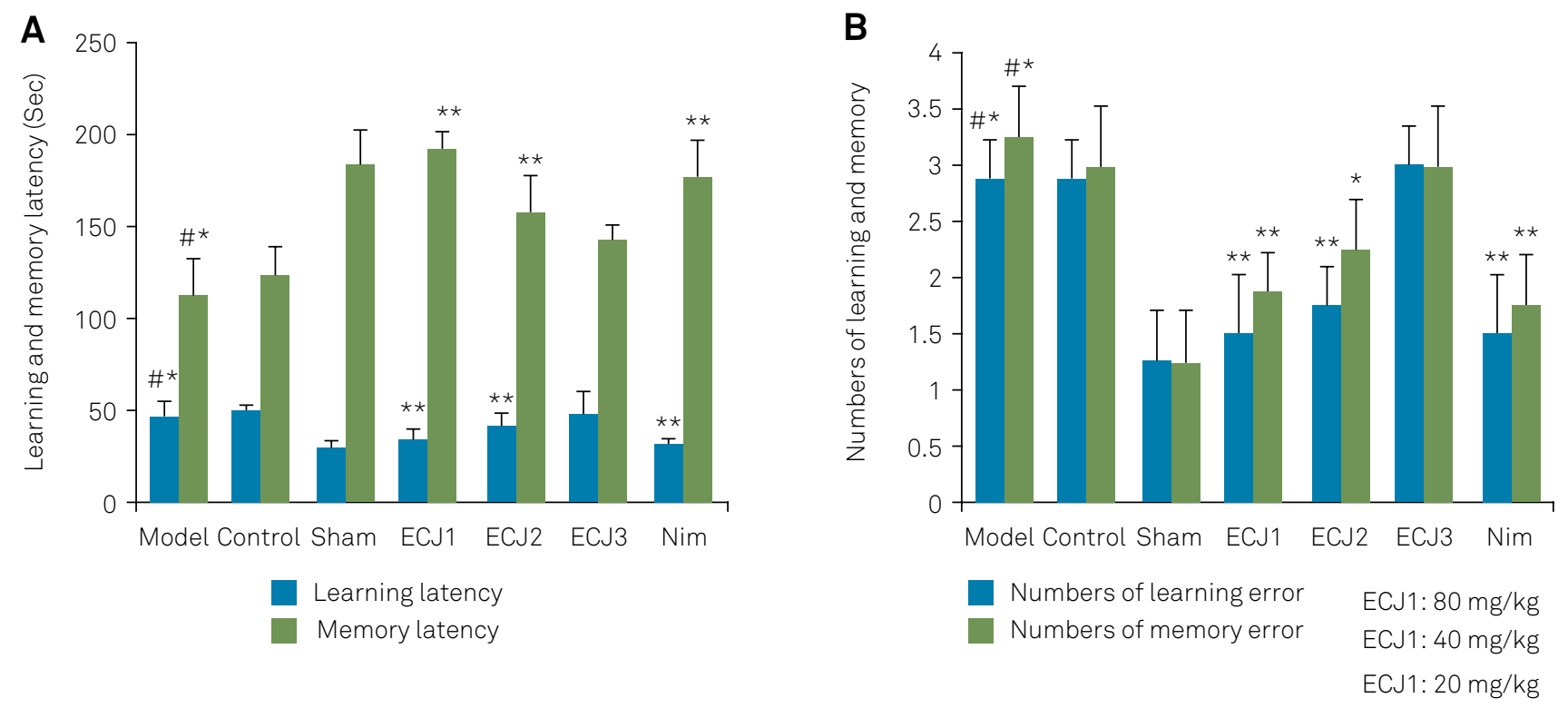

${ }^{\#} p<0.01$ vs Sham; ${ }^{*} p>0.05$ vs Control; ${ }^{* *} p<0.01$ vs Model; ECJ: extract of C. japonica; Nim: nimodipine

Figure 1. Effect of extract of C. japonica on the impairment of rat learning and memory function (means \pm SD, $n=8$ ). A. Effect of extract of C. japonica on impairment of rat learning and memory latency; B. Effect of extract of C. japonica on the increase of the number of learning errors and memory errors.
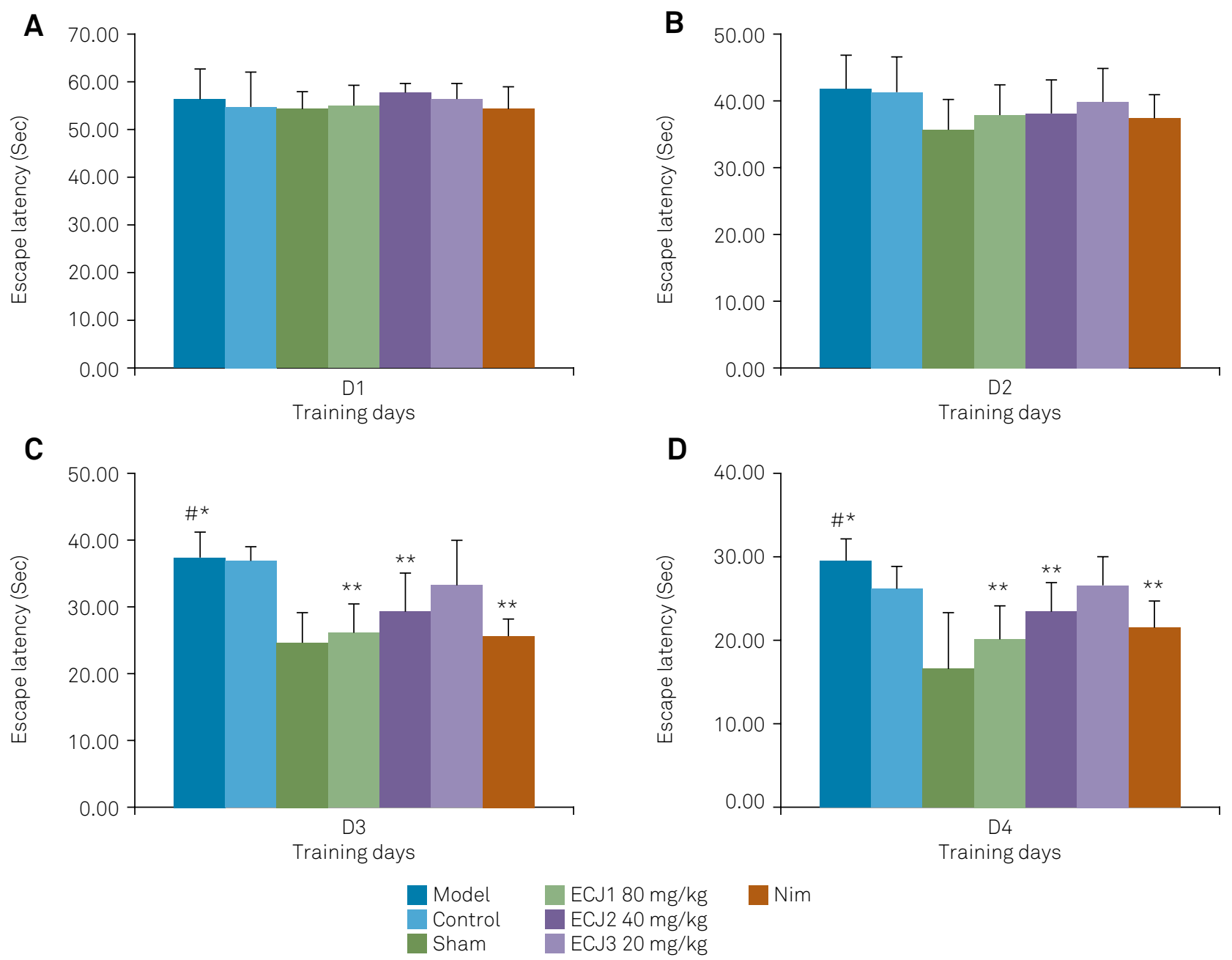

$\mathrm{Nim}$

${ }^{*} p<0.01$ vs Sham; ${ }^{*} p>0.05$ vs Control; ${ }^{* *} p<0.01$ vs Model; ECJ: extract of $C$. japonica; Nim: nimodipine.

Figure 2. Effects of extract of C. japonica on the impairment of rat place navigation (Morris water maze test, $m e a n s \pm S D, n=8$ ). A. Day 1 training; B. Day 2 training; C. Day 3 training; D. Day 4 training. 
Table. Protective effect of extract of $C$. japonica on impairment of rat spatial probe ability induced by cerebral ischemiareperfusion.

\begin{tabular}{|c|c|c|c|c|}
\hline Group & Dose (mg/kg) & Number of entries & Proportion of time (\%) & Proportion of swim distance (\%) \\
\hline Model & l & $1.38 \pm 0.52^{* \star *}$ & $22.94 \pm 0.11^{* * *}$ & $24.23 \pm 0.09^{*, * *}$ \\
\hline Control & / & $1.50 \pm 0.53$ & $21.94 \pm 0.08$ & $23.12 \pm 0.07$ \\
\hline Sham & / & $2.57 \pm 0.52$ & $38.07 \pm 0.09$ & $33.80 \pm 0.06$ \\
\hline \multirow{3}{*}{ Extract of C. japonica } & 80 & $2.50 \pm 0.53^{\star \star \star}$ & $33.47 \pm 0.07^{\star \star \star}$ & $33.05 \pm 0.05^{\star \star \star}$ \\
\hline & 40 & $2.25 \pm 0.71 * \star \star$ & $30.4 \pm 0.08 * \star \star$ & $30.5 \pm 0.07 * \star *$ \\
\hline & 20 & $1.63 \pm 0.52$ & $23.33 \pm 0.10$ & $22.73 \pm 0.11$ \\
\hline Nimodipine & 2 & $2.63 \pm 0.52^{* \star \star}$ & $33.21 \pm 0.08^{* \star *}$ & $32.4 \pm 0.06^{\star \star *}$ \\
\hline
\end{tabular}

${ }^{*} p<0.01$ vs Sham; ${ }^{* \star} p>0.05$ vs Control; $* * \star p<0.01$ vs Model.

those in the sham rat group. However, pretreatment with 40 and $80 \mathrm{mg} / \mathrm{kg}$ extract of $C$. japonica, or $2 \mathrm{mg} / \mathrm{kg}$ nimodipine had a significantly protective effect on the decrease in the spatial probe ability in rats.

\section{Effect of extract of $C$. japonica on the percentage of infarct volume}

The cerebral infarct volume measured using the TTC staining method is usually used as a direct indicator of middle cerebral artery occlusion injury. The results are shown in Figure 3; the average percentage of the infarct volume of the model group rats was $29 \%$, and the control group was $30 \%$. Pretreatment with extract of C. japonica $(40,80 \mathrm{mg} / \mathrm{kg}$ ) or nimodipine $(2 \mathrm{mg} / \mathrm{kg})$ markedly decreased the percentage of infarct volume in these rats (compared with the model group, $\mathrm{p}<0.01)$.

\section{Effect of extract of $C$. japonica on serum MDA level and LDH activity}

Like LDH leakage from brain cells to serum, MDA, a product of lipid peroxidation, has also been used to assess cerebral ischemia-reperfusion injury, indicated by increases of its activity in serum. As shown in Figure 4, in the model group and the control group, marked increases in serum MDA level and LDH activity were detected. Pretreatment with 40, $80 \mathrm{mg} / \mathrm{kg}$ extract of C. japonica significantly inhibited the elevation of serum MDA levels and LDH activity. The pretreatment of $2 \mathrm{mg} / \mathrm{kg}$ nimodipine had a similar protective effect.

\section{Determination of serum IgG present in brain parenchyma}

To demonstrate the mechanism of the protective effect of extract of $C$. japonica on cerebral ischemia-reperfusion injury, the BBB integrity was evaluated by detecting the serum IgG extravasation into the brain parenchyma. There is a minimal amount of serum IgG detected in brain parenchyma unless the BBB integrity is damaged. The results are shown in Figure 5, where pretreatment with $40,80 \mathrm{mg} / \mathrm{kg}$ extract of $C$. japonica or $2 \mathrm{mg} / \mathrm{kg}$ nimodipine significantly reduced the increase of IgG in the ipsilateral cortex, ipsilateral subcortex, contralateral cortex and contralateral subcortex induced by cerebral ischemia-reperfusion ( $p<0.01$ compared with the model group).

\section{DISCUSSION}

Camellia japonica is a popular garden plant, the leaves, seeds and flowers of which are widely used as traditional medicine. A previous study revealed that extracts of C.japonica obtained from leaves, seed and flowers have various biological activities ${ }^{8}$. Our previous study also showed that the extract of $C$. japonica from flowers has a protective effect on neuronal damage injured by anoxia-reoxygenation using a preconditioning method ${ }^{11}$. Moreover, pretreatment with a drug is a frequently-used method in the experimental study of cerebral ischemia-reperfusion injury ${ }^{21}$. Therefore, the present study was designed to evaluate the effect of extract of $C$. japonica on cerebral ischemia-reperfusion injury using the preconditioning method.

Middle cerebral artery occlusion is a widely-used model of focal cerebral ischemia-reperfusion injury according to previous reports ${ }^{18}$. In this study, we found that middle cerebral artery occlusion significantly impaired learning and memory functions of rats. Compared with the sham group, cerebral ischemia-reperfusion markedly increased learning and memory latency, number of learning errors and memory errors. The results of the place navigation trial also showed that a cerebral ischemia-reperfusion injury could markedly induce the impairment of place navigation ability. Moreover, cerebral ischemia-reperfusion injury also impaired the spatial probe ability of rats. Interestingly, these changes could significantly be inhibited by pretreatment with $40,80 \mathrm{mg} / \mathrm{kg}$ extract of C.japonica or $2 \mathrm{mg} / \mathrm{kg}$ nimodipine.

In order to further confirm the protection of extract of C. japonica against the rat ischemia-reperfusion injury, we measured the percentage of cerebral infarct volume, serum MDA (an oxidative stress biomarker) level and LDH activity. As we know, MDA is an indicator of lipid peroxidation $^{22}$, and LDH is a metabolic enzyme in neurons and is released into the blood from an injured neuron ${ }^{23}$. Therefore, an increase of serum MDA level and LDH activity may reflect the damage of neurons. Our results also showed that cerebral ischemia-reperfusion markedly increased the percentage of infarct volume, serum MDA level and LDH activity. Compared with the model group or control group, pretreatment with extract of C. japonica $(40,80 \mathrm{mg} / \mathrm{kg})$ or nimodipine $(2 \mathrm{mg} / \mathrm{kg})$ could significantly decrease the 
percentage of infarct volume, serum MDA level and LDH activity $(\mathrm{p}<0.01)$. These results provided direct evidence that extract of $C$. japonica has a significant neuroprotective effect on cerebral ischemia-reperfusion injury.

Moreover, disruption of the BBB is also one of the pathophysiological mechanisms of ischemic stroke, with elevated permeability and compromised barrier function ${ }^{24}$. The presence of serum IgG in brain parenchyma was assessed as an index of BBB damage ${ }^{25}$. As shown in our study, due to BBB disruption, extravasation of serum IgG into the brain parenchyma induced by ischemia-reperfusion injury was detected with ELISA. Not surprisingly, the pretreatment with 40, $80 \mathrm{mg} / \mathrm{kg}$ extract of $C$. japonica or $2 \mathrm{mg} / \mathrm{kg}$ nimodipine prior to the ischemic insult significantly inhibited the extravasation of serum IgG into the brain parenchyma, suggesting a protective effect on ischemic $\mathrm{BBB}$ damage.

In this study, we found that extract of $C$. japonica had protective effects on cerebral ischemia-reperfusion injury in rats. The mechanism of the protective effect may be related to the inhibition of lipid peroxidation and BBB compromise. A previous study reported that the constituents in the flowers of $C$. japonica contain several hydrolyzable tannins, triterpenes, acylated anthocyanins, and purine alkaloids ${ }^{10}$. Further studies are of crucial importance to elucidate the role of the constituents of extract of $C$. japonica in the neuroprotective effect.
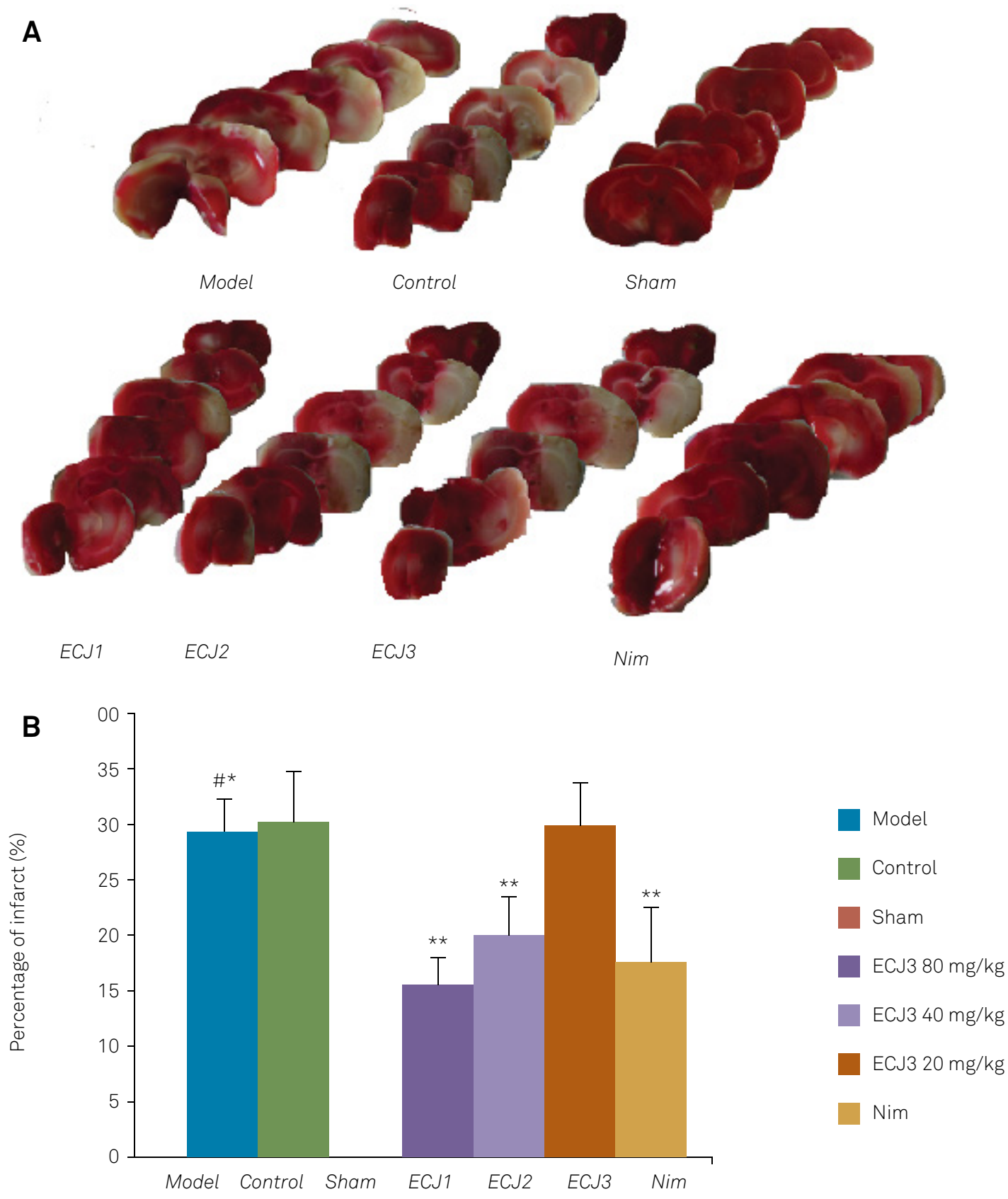

${ }^{\#} p<0.01$ vs Sham; ${ }^{*} p>0.05$ vs Control; ${ }^{* *} p<0.01$ vs Model; ECJ: extract of C. japonica; Nim: nimodipine.

Figure 3. Effect of extract of C. japonica on the percentage of cerebral infarct in rats. A. Representative TTC-stained coronal brain sections; B. Effect of extract of C. japonica on the percentage of infarct (means $\pm S D, n=8$ ). 
A

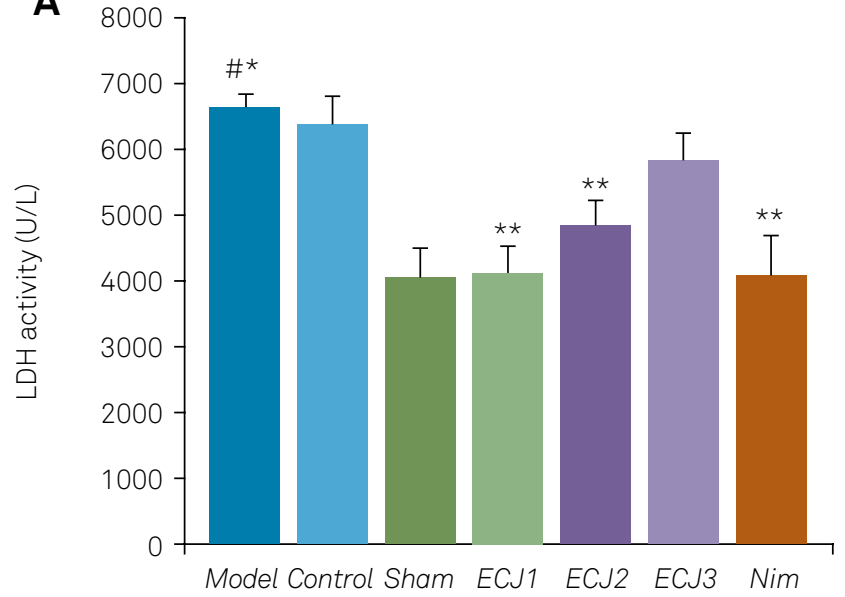

B

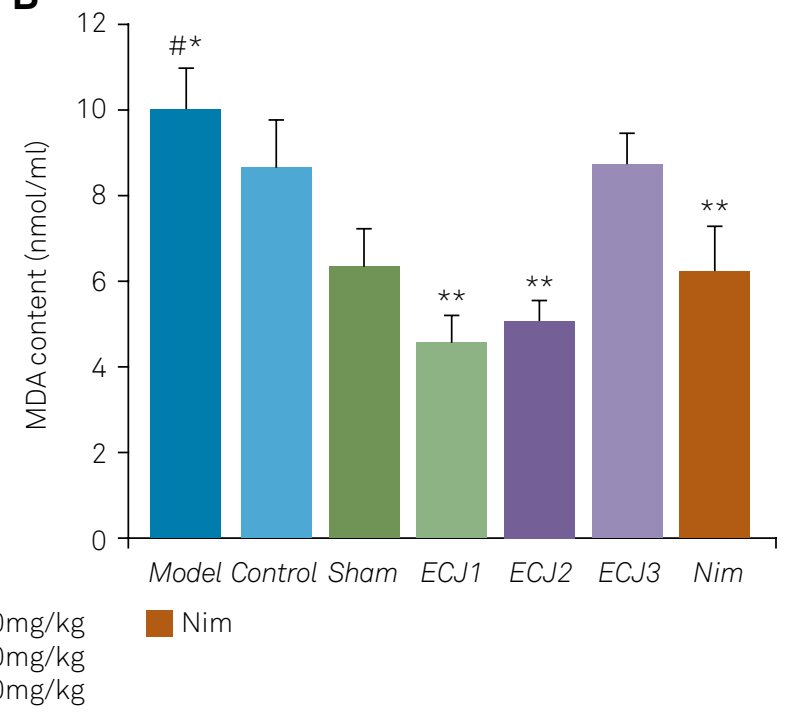

${ }^{\#} p<0.01$ vs Sham; ${ }^{*} p>0.05$ vs Control; ${ }^{* *} p<0.01$ vs Model; ECJ: extract of C. japonica; Nim: nimodipine.

Figure 4. Effect of extract of C. japonica on increases of LDH activity and MDA content in rat serum (means $\pm S D, n=8)$. A. Changes in the LDH activity; B. Changes in the MDA level.

A
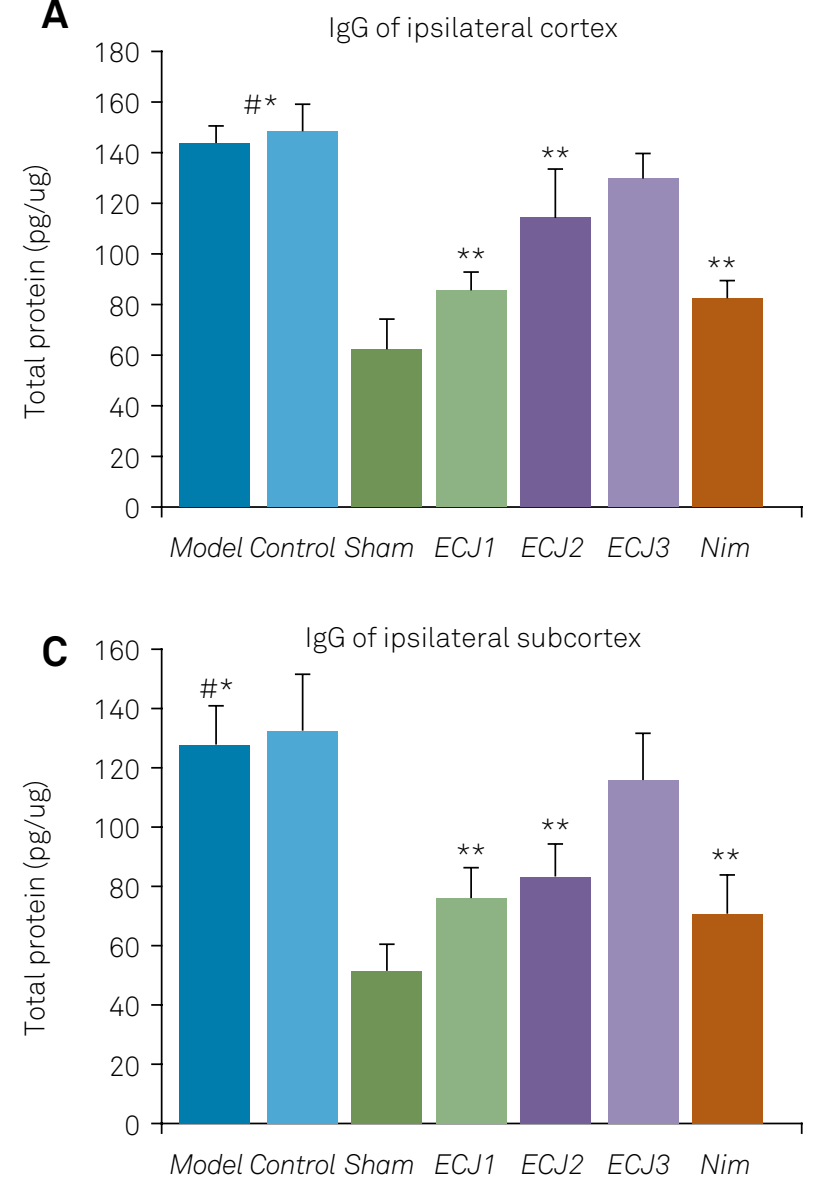
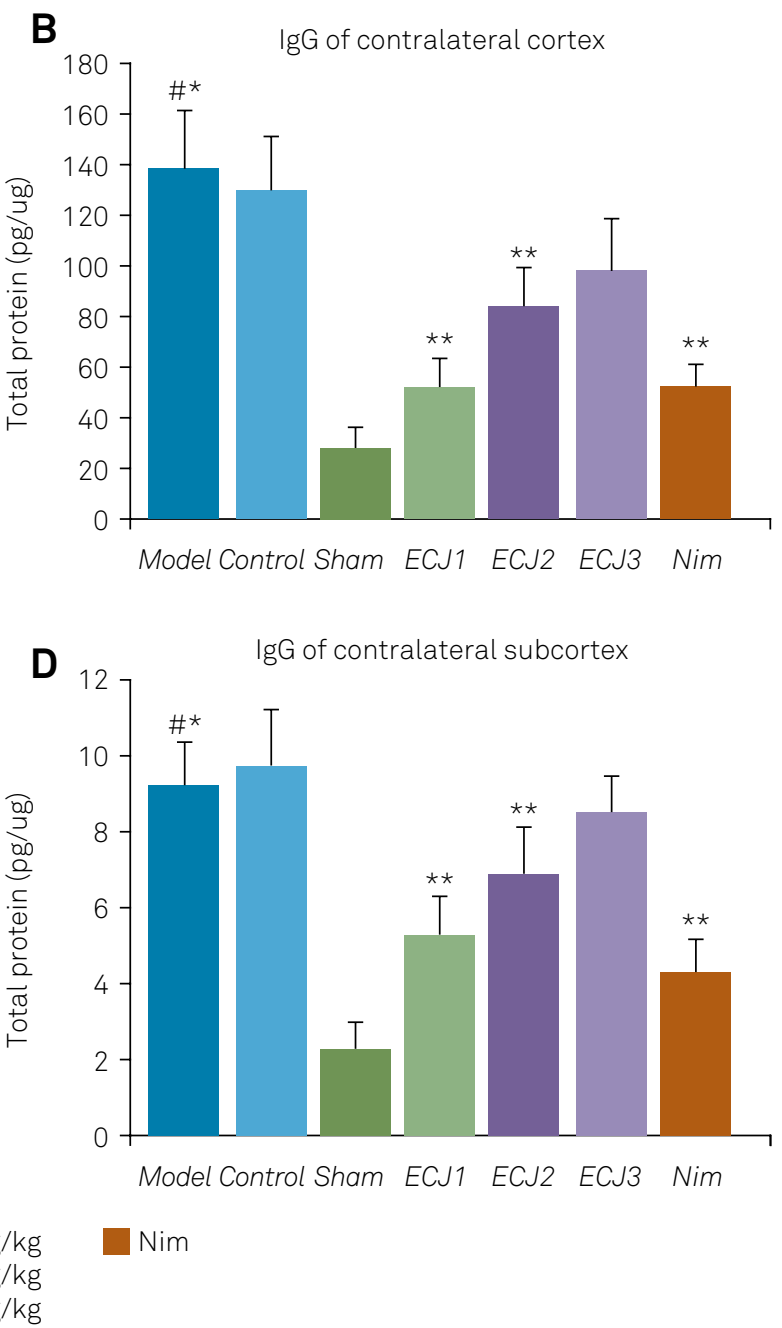

${ }^{*} p<0.01$ vs Sham; ${ }^{*} p>0.05$ vs Control; ** $p<0.01$ vs Model; ECJ: extract of C. japonica; Nim: nimodipine.

Figure 5. Determination of serum IgG present in brain parenchyma (means $\pm S D, n=8$ ). A. Effect of extract of $C$. japonica on extravasation of serum IgG in the ipsilateral cortex; B. Effect of extract of C. japonica on extravasation of serum lgG in the contralateral cortex; C. Effect of extract of C. japonica on extravasation of serum IgG in the ipsilateral subcortex; D. Effect of extract of C. japonica on extravasation of serum IgG in the contralateral subcortex. 
1. Liu Z, Chen X, Gao Y, Sun S, Yang L, Yang Q et al. Involvement of GluR2 up-regulation in neuroprotection by electroacupuncture pretreatment via cannabinoid CB1 receptor in mice. Scient Rep.. 2015 Apr;5:9490. https://doi.org/10.1038/srep09490

2. Woodruff TM, Thundyil J, Tang SC, Sobey CG, Taylor SM, Arumugam TV. Pathophysiology, treatment, and animal and cellular models of human ischemic stroke. Mol Neurodegener. 2011 Jan;6(1):11. https://doi.org/10.1186/1750-1326-6-11

3. Kumar GP, Khanum F. Neuroprotective potential of phytochemicals. Pharmacogn Rev. 2012 Jul;6(12):81-90. https://doi.org/10.4103/0973-7847.99898

4. Wang T, Duan S, Wang H, Sun S, Han B, Fu F. Neurological function following cerebral ischemia/reperfusion is improved by the Ruyi Zhenbao pill in a rats. Biomed Rep. 2016 Feb;4(2):161-6. https://doi.org/10.3892/br.2016.568

5. Lee JH, Kim JW, Ko NY, Mun SH, Kim DK, Kim JD et al. Camellia japonica suppresses immunoglobulin E-mediated allergic response by the inhibition of Syk kinase activation in mast cells. Clin Exp Allergy. 2008 May;38(5):794-804. https://doi.org/10.1111/j.1365-2222.2008.02936.x

6. Kim KY, Davidson PM, Chung HJ. Antibacterial activity in extracts of Camellia japonica L. petals and its application to a model food system. J Food Prot. 2001 Aug;64(8):1255-60. https://doi.org/10.4315/0362-028X-64.8.1255

7. Onodera K, Hanashiro K, Yasumoto T. Camellianoside, a novel antioxidant glycoside from the leaves of Camellia japonica. Biosci Biotechnol Biochem. 2006 Aug;70(8):1995-8. https://doi.org/10.1271/bbb.60112

8. Piao MJ, Yoo ES, Koh YS, Kang HK, Kim J, Kim YJ et al. Antioxidant effects of the ethanol extract from flower of Camellia japonica via scavenging of reactive oxygen species and induction of antioxidant enzymes. Int J Mol Sci. 2011;12(4):2618-30. https://doi.org/10.3390/ijms12042618

9. Woo Y, Lee H, Jeong YS, Shin GY, Oh JG, Kim JS et al. Antioxidant potential of selected korean edible plant extracts. BioMed Res Int. 2017;2017:7695605. https://doi.org/10.1155/2017/7695605

10. Park SH, Shim BS, Yoon JS, Lee HH, Lee HW, Yoo SB et al. Vascular protective effect of an ethanol extract of Camellia japonica fruit: endothelium-dependent relaxation of coronary artery and reduction of smooth muscle cell migration. Oxid Med Cell Longev.. 2016;2016:ID6309565. https://doi.org/10.1155/2016/6309565

11. Weizhuo Lu GC, Wang H, Chu S. Protective effect of extract of Camellia japonica $L$ on hippocampal neurons subjected to anoxia-reoxygenation injury. J Huainan Vocat Tech Coll. 2017;17(4):3.

12. Wen JY, Chen ZW. Protective effect of pharmacological preconditioning of total flavones of abelmoschl manihot on cerebral ischemic reperfusion injury in rats. Am J Chin Med. 2007;35(4):653-61. https://doi.org/10.1142/S0192415X07005144

13. Zhao Q, Cheng X, Wang X, Wang J, Zhu Y, Ma X. Neuroprotective effect and mechanism of Mu-Xiang-You-Fang on cerebral ischemia-reperfusion injury in rats.J Ethnopharmacol. 2016 Nov 4;192:140-7. https://doi.org/10.1016/j.jep.2016.07.016
14. Zhu L, Zhang L, Zhan L, Lu X, Peng J, Liang L et al. The effects of Zibu Piyin Recipe components on scopolamine-induced learning and memory impairment in the mouse. J Ethnopharmacol. 2014;151(1):576-82. https://doi.org/10.1016/j.jep.2013.11.018

15. Heo YM, Shin MS, Lee JM, Kim CJ, Baek SB, Kim KH et al. Treadmill exercise ameliorates short-term memory disturbance in scopolamine-induced amnesia rats. Int Neurourol J. 2014 Mar;18(1):16-22. https://doi.org/10.5213/inj.2014.18.1.16

16. Su Z, Han D, Sun B, Qiu J, Li Y, Li M et al. Heat stress preconditioning improves cognitive outcome after diffuse axonal injury in rats. J Neurotrauma. 2009 Oct;26(10):1695-706. https://doi.org/10.1089/neu.2008.0519

17. Liu ZW, Zhang T, Yang Z. Involvement of nitric oxide in spatial memory deficits in status epilepticus rats. Neurochem Res. 2007 Nov;32(11):1875-83. https://doi.org/10.1007/s11064-007-9374-1

18. Chu B, Zhou Y, Zhai H, Li L, Sun L, Li Y. The role of microRNA-146a in regulating the expression of IRAK1 in cerebral ischemia-reperfusion injury. Can J Physiol Pharmacol. 2018 Jun;96(6):611-7. https://doi.org/10.1139/cjpp-2017-0586

19. Zhang L, Fu F, Zhang X, Zhu M, Wang T, Fan H. Escin attenuates cognitive deficits and hippocampal injury after transient global cerebral ischemia in mice via regulating certain inflammatory genes. Neurochem Int. 2010 Sep;57(2):119-27. https://doi.org/10.1016/j.neuint.2010.05.001

20. Tao J, Cui Y, Duan Y, Zhang N, Wang C, Zhang F. Puerarin attenuates locomotor and cognitive deficits as well as hippocampal neuronal injury through the PI3K/ Akt1/GSK-3 $\beta$ signaling pathway in an in vivo model of cerebral ischemia. Oncotarget. $2017 \mathrm{Nov}$;8(63):106283-95. https://doi.org/10.18632/oncotarget.22290

21. Xiao Z, Ren P, Chao Y, Wang Q, Kuai J, Lv M et al. Protective role of isoflurane pretreatment in rats with focal cerebral ischemia and the underlying molecular mechanism. Mol Med Rep. $2015 \mathrm{Jul} ; 12(1): 675-83$. https://doi.org/10.3892/mmr.2015.3408

22. Liang G, Shi B, Luo W, Yang J. The protective effect of caffeic acid on global cerebral ischemia-reperfusion injury in rats. Behav Brain Funct. 2015 Apr;11:18. https://doi.org/10.1186/s12993-015-0064-X

23. Luo SY, Chen S, Qin YD, Chen ZW. Urotensin-receptor antagonist SB-710411 protects rat heart against ischemia-reperfusion injury via RhoA/ ROCK pathway. PLoS One. 2016 Jan;11(1):e0146094. https://doi.org/10.1371/journal.pone.0146094

24. Obermeier B, Daneman R, Ransohoff RM. Development, maintenance and disruption of the blood-brain barrier. Nat Med. 2013 Dec;19(12):1584-96. https://doi.org/10.1038/nm.3407

25. DeMars KM, McCrea AO, Siwarski DM, Sanz BD, Yang C, Candelario-Jalil E. Protective effects of L-902,688, a prostanoid EP4 receptor agonist, against acute blood-brain barrier damage in experimental ischemic stroke. Front Neurosci. 2018;12:89. https://doi.org/10.3389/fnins.2018.00089 